\title{
Comparison of the Effectiveness of Mindfulness- Based Stress Reduction Group Therapy With Acceptance and Commitment Therapy on Severity of Pain and Health-Related Quality of Life in Patients With Migraine
}

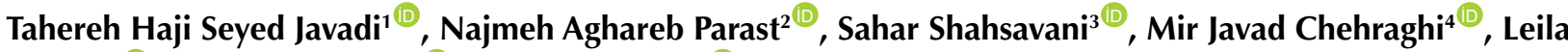 \\ Razavi $^{5^{*} \mathbb{D}}$, Soheila Rahmani ${ }^{\circledR}$, Somayeh Nejati ${ }^{(\mathbb{D}}$ \\ ${ }^{1}$ Department of Psychology, Kish International Branch, Islamic Azad University, Kish Island, Iran \\ ${ }^{2}$ School of Psychology and Educational Sciences, Ferdosi University of Mashhad, Mashhad, Iran \\ ${ }^{3}$ School of Psychology and Educational Sciences, Islamic Azad University of SouthTehran Branch, Tehran, Iran \\ ${ }^{4}$ School of Psychology and Educational Sciences, The Islamic Azad University of South Tehran Branch, Tehran, Iran \\ ${ }^{5}$ School of Psychology and Educational Sciences, Islamic Azad University of Qom, Qom, Iran \\ ${ }^{6}$ Department of Psychology, Karaj Branch, Islamic Azad University, Karaj, Iran \\ 'School of Psychology and Educational Sciences, University of Semnan, Semnan, Iran
}

\begin{abstract}
Background: Considering the prevalence of migraine and its detrimental effects on functioning, physical health, and quality of life as well as its psychosocial and social risks. The purpose of this study was to compare the effectiveness of mindfulness-based stress reduction treatment with treatment based on acceptance and commitment to the severity of pain and health-related quality of life in migraine patients.

Methods: In this study, a semi-experimental design used with pre-test, post-test, a 3-month follow-up, and a control group. Using purposive sampling and considering the inclusion criteria, 45 patients with migraine diagnosis selected from among those referring to the neurology department of Imam Hossein hospital in Tehran. They were then randomly assigned to two experimental groups and a control group. The first experimental group received group therapy based on mindfulness $(n=15$; 90-minute sessions), the second experimental group received acceptance and commitment based intervention ( $n=15 ; 90$-minute sessions), and the control group $(n=15)$ received no intervention. All subjects responded to pain intensity and health-related quality of life questionnaires before the intervention (pre-test), after the intervention (post-test), and 3 months after the intervention (follow-up). One-way ANOVA analyzed the collected data.

Results: The findings showed that mean scores for the 2 experimental groups were significantly different from the control group in the post-test and follow-up phases in terms of severity of pain and health-related quality of life, while the mean scores for the two experimental groups did not differ significantly. The results emphasize the importance of these interventions for chronic diseases and offer new horizons in clinical interventions.

Conclusion: The results of this study showed that mindfulness-based stress reduction therapy and acceptance and commitment therapy could positively affect the severity of pain and health-related quality of life in migraine patients, and any of them can be used to improve the variables mentioned above.

Keywords: Mindfulness-based therapy; Acceptance; Commitment, The severity of pain; Health-related quality of life; Migraine.
\end{abstract}

\author{
*Correspondence to \\ Leila Razavi, MA in General \\ Psychology, School of \\ Psychology and Educational \\ Sciences, Islamic Azad \\ University of Qom, Qom, Iran. \\ Tel: +989126511300, \\ Email: r.leila1355@gmail.com
}

Published online August 31, 2019

Citation: Haji Seyed Javadi T, Aghareb Parast N, Shahsavani S, Chehraghi MJ, Razavi L, Rahmani S. Comparison of the effectiveness of mindfulness-based stress reduction group therapy with acceptance and commitment therapy on severity of pain and health-related quality of life in patients with migraine. Int Clin Neurosci J. 2019;6(3):111-117. doi:10.15171/icnj.2019.21.

\section{Introduction}

Migraine is a debilitating headache $e^{1}$ and a neurovascular disorder ${ }^{2}$ described as the third common disorder and the seventh cause of disability in the world. ${ }^{3}$ This type of headache occurs periodically, usually lasting from 4 to 72 hours. The occurrence rate of migraine per year is $17 \%$ in women and $6 \%$ in men, and the highest prevalence is in the age group of 35 to 45 years old. ${ }^{4}$ Migraine headaches

(C) 2019 The Author(s). This is an open access article distributed under the terms of the Creative Commons Attribution License (http:// creativecommons.org/licenses/by/4.0/), which permits unrestricted use, distribution, and reproduction in any medium, provided the original work is properly cited. 
are usually associated with dizziness, nausea, and sensitivity to light and sound. ${ }^{5}$ This condition is highly hereditary, but factors such as stress, depression, sleep disorders, hormonal imbalance (menstruation), fatigue, and some foods can trigger migraines. ${ }^{6}$ This chronic and prolonged pain disrupts healthy life and negatively affects physical, psychological, and social health as well as the quality of life. ${ }^{3,7}$ Studies indicate that mental disorders (anxiety, depression, and lack of social support) are more common in people with migraine headaches. This leads to a decrease in quality of life and ultimately, mental disorders. ${ }^{8,9}$ Kollewe et al showed that health-related quality of life, as a multi-dimensional concept, can be considered as the most important goal in treating these patients, in order to reduce symptoms and improve their health and psychosocial functions. ${ }^{10}$ Findings by Shaik et al indicated that women with migraine experience lower levels of physical and psychological quality of life compared to healthy people. Therefore, the frequency and severity of pain are related to the quality of life in women with migraine, and the higher the number of days and the severity of the pain, the lower their quality of life. ${ }^{11}$

The findings suggest that psychological treatments such as mindfulness or acceptance and commitment approaches can help patients with chronic pain. Mindfulness-based treatment is the deliberate and uncritical attention to the present moment which previously taken for granted. ${ }^{12}$ By practicing mindfulness techniques, people acquire greater awareness about their daily activities, becoming aware of the automatic functioning of their minds in the past and the future and gain more control over their minds by constant awareness about their thoughts, emotions, and physical states. In this way, they are set free from the automatic mind, which focused on the future or the past. ${ }^{13}$ Research findings show that mindfulness can be useful in reducing stress and improving the quality of life in patients with migraine. ${ }^{14}$ Zare et al concluded that mindfulness-based stress reduction therapy helps to improve mental health and reduce perceived pain. ${ }^{15}$ Also, many studies have confirmed the positive effects of mindfulness-based stress reduction therapy in chronic patients. ${ }^{16-19}$ Nathan et $\mathrm{a}^{20}$ investigated the effect of stress reduction through mindfulness on pain-related disorders, pain intensity, and health-related quality of life in diabetic patients. The results of this study showed positive effects of mindfulness on patients' performance and their quality of life and reduction in pain catastrophizing and pain intensity. Bakhshani et $\mathrm{al}^{21}$ investigated the effect of mindfulness-based stress reduction on the severity of pain and quality of life in patients with chronic headache. Their findings showed significantly reduced pain perception and improved quality of life in the intervention group compared to the control group. They concluded that this treatment could use as a non-pharmacological intervention to improve the quality of life and develop pain-coping strategies in patients with chronic headache.
On the other hand, acceptance and commitment therapy is the only psychological and empirical intervention in which acceptance strategies combined with commitment and behavioral change strategies to increase psychological flexibility and committed action in order to achieve goals based on values. ${ }^{22}$ This theory considers avoidance of pain and stress as the main problem of patients leading to disability and reduced satisfaction in life. Therefore, the primary method of treatment in acceptance and commitment therapy is to expose patients to situations that previously avoided. ${ }^{23}$ This treatment works by increasing people's ability to stay active and act following their values to improve the quality of life and their functioning. ${ }^{24}$ In this regard, Müller et $\mathrm{al}^{25}$ examined the effectiveness of acceptance and commitment-based treatment in migraine patients. According to their findings, this treatment leads to pain reduction and symptom relief by increasing psychological flexibility. A study by Dindo et $\mathrm{al}^{26}$ showed that acceptance and commitment therapy increases the acceptability of pain and reduces pain in patients. The findings reported by Bastami et al showed that acceptance and commitment intervention in patients with type 2 diabetes significantly increased the quality of life in the experimental group compared to the control group, after eight sessions of intervention, and lasted after 3 months in the follow-up phase. ${ }^{27}$

What adds to the importance of this study is the application of relatively new psychological treatments that help improve patients' quality of life and performance. However, application of this treatment requires further studies. To this end, the effectiveness of mindfulnessbased therapy can compare with other treatments which have adequate research support- e.g., acceptance and commitment-based therapy. So far, this topic has not researched in Iran. Therefore, the purpose of this study is to compare the effectiveness of mindfulness-based stress reduction group therapy with acceptance and commitment-based therapy on the severity of pain and health-related quality of life in migraine patients.

\section{Methods}

This study was semi-experimental in design using pretest, post-test, control group, and a follow-up period of 3 months. The target population included all migraine patients referred to the neurology department of Imam Hossein hospital in Tehran during the spring of 2018. The sampling process started by selecting 100 patients from the list provided by the hospital, and invitations sent to them via SMS. The screening was carried out on those willing to participate in the study, and 45 subjects selected through purposive sampling. They were then randomly assigned to 3 groups, 2 experimental groups (15 subjects for mindfulness therapy intervention, 15 subjects for acceptance and commitment treatment), and a control group (15 subjects receiving no intervention). The criteria for including subjects in the study were: (1) Diagnosis of 
migraine by neurologists or psychiatrists the absence of other acute or chronic disorders. (2) Not using psychiatric drugs during the study. (3) The minimum education level of a high school diploma. (4) No history of psychotherapy or drug treatment before participating in this research. (5) Minimum age of 20 years, not suffering from other physical illnesses or severe psychiatric disorders. (6) Absence of other disabling or chronic diseases such as kidney, liver, or cardiovascular diseases. (7) Being clean from drug abuse and the patient's willingness to participate in the research. The criteria for exclusion include the reluctance to cooperate in the treatment sessions, and absence in more than 2 sessions. Then, the subjects in experimental groups underwent the treatments mentioned above in 8 (90 minutes) weekly sessions for 2 months. The control group did not receive any treatments. Due to ethical considerations at the end of the research, the treatment also offered to the control group.

\section{McGill Pain Questionnaire}

The McGill Pain Questionnaire is the most reliable instrument for measuring pain (especially chronic and resistant pain). The most critical requirements of measurement instruments are accuracy, reliability, and validity, which are all fulfilled by the McGill pain questionnaire. ${ }^{28}$ In the present study, Cronbach's alpha coefficient for reliability was 0.73 . This questionnaire allows the patients to express their perception of pain in sensory, affective, and evaluative dimensions. Another feature of the McGill Pain Questionnaire is its potential value in the diagnosis of differential pain. This questionnaire was used by Melzack (1973) on 297 patients suffering from various types of pain. Initially, specialists had reported 102 words that were commonly used by patients to express their pain. After numerous studies, McGill Pain Questionnaire has accepted as a reliable instrument for studying and evaluating pain through various clinical methods. The main part of this questionnaire consists of 20 sets of verbal descriptors related to the mental perception of pain. ${ }^{29}$

\section{Quality of Life Questionnaire (SF-36)}

This questionnaire is designed by Ware et al. ${ }^{30}$ It is a comprehensive questionnaire for measuring the quality of life in all health-related aspects. The questionnaire examines eight dimensions for quality of life consisting of 36 items that can be completed by respondents or through interviews. It could use for different age groups and diseases. Reliability and validity of this questionnaire were approved by Ware et al in 1988. The questionnaire shows people's perceptions of their quality of life in 8 dimensions whose scores may vary from 0 to 100 . The score of 100 represents the ideal conditions, and zero indicates the worst conditions for each dimension. These dimensions include physical functioning, role limitations due to physical health problems, bodily pain, vitality, general health, mental health, role limitations due to emotional problems, and social functioning. This questionnaire has international reliability and validity. ${ }^{31}$ In Iran, it has translated by the Institute for Health Sciences of the Academic Center for Education, Culture, and Research. This institute has also verified the reliability and validity of the SF-36 questionnaire. Cronbach's alpha coefficient as a measure of its reliability has calculated between $77 \%$ and $95 \%$ for all dimensions except for vitality, whose reliability coefficient was 65\%. Therefore, the reliability and validity of this questionnaire have approved for the Iranian population. In a study by Montazeri et al, ${ }^{32}$ internal consistency analysis showed that except for the vitality scale (Cronbach's alpha $=65 \%$ ), other scales of the SF-36 questionnaire had the minimum reliability coefficients ranging from $77 \%$ to $90 \%$. Also, the convergent validity test using the correlation of each item with the hypothesized scale yielded favorable results, and all the correlation coefficients exceeded the recommended value of $4 \% .^{33}$

\section{Results}

Mean, standard deviation, frequency distribution table, and one-way analysis of variance (ANOVA) were employed to analyze the collected data using SPSS-21 software. The results have shown in Tables 1 and 2. In this study, 45 patients with migraine studied. The age of the participants ranged from 20 to 45 years old, and they assigned to 3 groups ( 15 subjects in the mindfulnessbased intervention group, 15 subjects in the acceptance and commitment based intervention group, and 15 subjects in the control group).

Considering that the significance level of the Kolmogorov-Smirnov Z statistic for all of the research variables are higher than 0.05 in both measurement intervals and for all the groups, it could argue with a 95\% certainty that all the research variables in this study have normal distributions. One-way ANOVA was used to examine the homogeneity of the 3 research groups (control/experimental) in pre-test scores. The results reported in Table 2.

\section{Statistical Results}

Considering that the observed F statistic values (for both research variables and their components) are smaller than the critical value of $\mathrm{F}_{0.05}$, with 42 and 2 degrees of freedom (3.22), the null hypothesis of lack of difference between mean values of pre-test scores in the 3 research groups is confirmed.

\section{Discussion}

The results of this study regarding the positive effects of mindfulness-based stress reduction on the severity of pain and health-related quality of life in migraine patients indicated that the severity of pain and healthrelated quality of life in these patients were improved. The 
Table 1. Results of the Kolmogorov-Smirnov Test for the Normality of the Data

\begin{tabular}{|c|c|c|c|c|c|c|c|c|c|c|}
\hline \multirow{2}{*}{ Component/ Variable } & & \multicolumn{3}{|c|}{$\begin{array}{c}\text { Acceptance and Commitment Based } \\
\text { Therapy }\end{array}$} & \multicolumn{3}{|c|}{ Mindfulness-Based Stress Reduction } & \multicolumn{3}{|c|}{ Control Group } \\
\hline & & Mean & SD & $\begin{array}{c}\text { Z Statistic } \\
(P \text { Value })\end{array}$ & Mean & SD & $\begin{array}{c}\text { Z Statistic } \\
(P \text { Value })\end{array}$ & Mean & SD & $\begin{array}{c}\text { Z Statistic } \\
(P \text { Value })\end{array}$ \\
\hline \multirow{2}{*}{ Severity of pain } & Pre-test & 12.40 & 1.77 & $0.903(0.389)$ & 12.20 & 2.46 & $0.652(0.789)$ & 11.80 & 2.65 & $0.547(0.926)$ \\
\hline & Post-test & 6.73 & 1.53 & $0.841(0.480)$ & 7.47 & 1.19 & $0.801(0.543)$ & 11.53 & 2.20 & $0.578(0.892)$ \\
\hline \multirow{2}{*}{ Physical functioning } & Pre-test & 81.20 & 9.65 & $0.542(0.931)$ & 78.00 & 10.49 & $0.823(0.507)$ & 81.67 & 6.73 & $0.865(0.443)$ \\
\hline & Post-test & 95.67 & 4.58 & $0.938(0.343)$ & 90.00 & 8.24 & $0.904(0.388)$ & 80.33 & 6.67 & $1.128(0.157)$ \\
\hline \multirow{2}{*}{$\begin{array}{l}\text { Role limitations due to } \\
\text { physical health problems }\end{array}$} & Pre-test & 38.33 & 24.76 & $1.181(0.123)$ & 40.00 & 24.64 & $1.068(0.204)$ & 38.33 & 31.15 & $0.828(0.499)$ \\
\hline & Post-test & 68.33 & 22.09 & $0.847(0.471)$ & 56.67 & 14.84 & $1.317(0.062)$ & 43.33 & 30.57 & $1.003(0.267)$ \\
\hline \multirow{2}{*}{$\begin{array}{l}\text { Role limitations due to } \\
\text { emotional problems }\end{array}$} & Pre-test & 22.22 & 27.22 & $1.263(0.082)$ & 20.07 & 0.70 & $1.050(0.220)$ & 20.09 & 14.55 & $1.088(0.188)$ \\
\hline & Post-test & 31.11 & 32.04 & $1.165(0.132)$ & 31.60 & 10.41 & $0.925(0.359)$ & 20.00 & 41.40 & $0.883(0.417)$ \\
\hline \multirow{2}{*}{ Vitality } & Pre-test & 27.33 & 12.37 & $0.614)(0.845$ & 25.00 & 10.35 & $0.904(0.388)$ & 31.33 & 14.08 & $0.557(0.916)$ \\
\hline & Post-test & 59.33 & 8.42 & $0.768(0.598)$ & 55.00 & 10.00 & $0.612(0.847)$ & 33.00 & 13.07 & $0.672(0.758)$ \\
\hline \multirow{2}{*}{ Emotional health } & Pre-test & 33.60 & 8.79 & $1.183(0.121)$ & 33.07 & 11.06 & $0.793(0.556)$ & 32.27 & 10.08 & $0.605(0.858)$ \\
\hline & Post-test & 58.13 & 10.01 & $0.761(0.608)$ & 54.47 & 9.85 & $0.779(0.579)$ & 38.13 & 11.20 & $0.558(0.914)$ \\
\hline \multirow{2}{*}{ Social functioning } & Pre-test & 39.17 & 16.95 & $0.797(0.549)$ & 41.67 & 13.91 & $0.805(0.536)$ & 43.33 & 17.59 & $0.632(0.819)$ \\
\hline & Post-test & 73.53 & 12.41 & $0.570(0.902)$ & 9.17 & 17.34 & $0.909(0.380)$ & 45.83 & 16.14 & $0.656(0.782)$ \\
\hline \multirow{2}{*}{ Pain } & Pre-test & 56.83 & 19.54 & $0.759(0.612)$ & 46.33 & 13.75 & $0.666(0.767)$ & 58.83 & 23.66 & $0.850(0.465)$ \\
\hline & Post-test & 90.17 & 11.36 & $1.317(0.062)$ & 80.83 & 16.28 & $0.707(0.700)$ & 60.37 & 22.85 & $0.798(0.547)$ \\
\hline \multirow{2}{*}{ General health } & Pre-test & 29.00 & 10.39 & $0.974(0.298)$ & 31.33 & 7.43 & $0.666(0.767)$ & 37.00 & 11.77 & $0.738(0.647)$ \\
\hline & Post-test & 62.00 & 10.32 & $0.631(0.821)$ & 58.00 & 10.99 & $0.707(0.700)$ & 42.33 & 10.83 & $0.785(0.568)$ \\
\hline \multirow{2}{*}{ Total quality of life score } & Pre-test & 40.96 & 5.27 & $0.490(0.970)$ & 39.43 & 4.91 & $0.661(0.775)$ & 42.86 & 8.39 & $0.453(0.987)$ \\
\hline & Post-test & 67.28 & 4.79 & $0.836(0.487)$ & 60.72 & 4.64 & $0.516(0.953)$ & 45.41 & 10.55 & $0.468(0.981)$ \\
\hline
\end{tabular}

3-month follow-up also confirmed the effectiveness and sustainability of the treatment results. These findings are consistent with the results reported in other studies. ${ }^{18}$ The findings reported by Lee et $\mathrm{al}^{10}$ showed that mindfulnessbased stress reduction therapy improved the physical and mental conditions of patients, as well as their quality of life by reducing distress and pain. Another study by Omidi et al indicated a significant difference in the quality of life between the intervention and control groups during the post-test, and this treatment was effective in improving the quality of life in cardiovascular patients. ${ }^{29}$

Mindfulness-based stress reduction therapy has positive effects on migraine because this therapy emphasizes abandoning the internal struggle, selfacceptance without judgment, and enhancing awareness of the present moment. ${ }^{34}$ The techniques used in this type of therapy not only raise awareness and increase spirituality but also improve mental health and quality of life. ${ }^{35}$ Mindfulness-based stress reduction employs 2 essential techniques (observation and acceptance), which help in reducing depression, anxiety, and stress symptoms .worries, negative thoughts, and emotional distress. ${ }^{36}$ This treatment also improves well-being and self-esteem ${ }^{37}$ and leads to better physical health. ${ }^{38}$ Patients gain the ability to improve the quality of their lives ${ }^{14}$ by learning autonomy and flexibility in dealing with stressful events and acquiring mental and physical skills to change the challenge. ${ }^{39}$ Mindfulness training involves paying attention to the present moment and particular emotions such as physical sensations in the body; thus, the mind focuses on thoughts, emotions, voices, or other physical feelings and remembers the content of this awareness. As a result, attention gradually shifts back to the present from the past and future. This prevents thoughts from deviating from reality. Regular observation of thoughts makes it possible to see similar thought patterns merely as thoughts (not the reality itself). ${ }^{40}$ In the present study, mindfulness-based stress reduction techniques have reduced pain and improved quality of life in people with migraine.

In this study, investigating the effectiveness of acceptance and commitment-based therapy on the severity of pain and health-related quality of life in people with migraine, showed that this treatment has been effective in reducing the severity of pain and improving healthrelated quality of life. Although no similar research has previously done in the population of migraine patients, our results are consistent with other findings. ${ }^{41}$ Clinical studies emphasize the importance of acceptance-based strategies in reducing pain symptoms ${ }^{42}$ and increasing 
Table 2. One-way ANOVA Test Results for Comparing Pre-test Scores of the 3 Research Groups

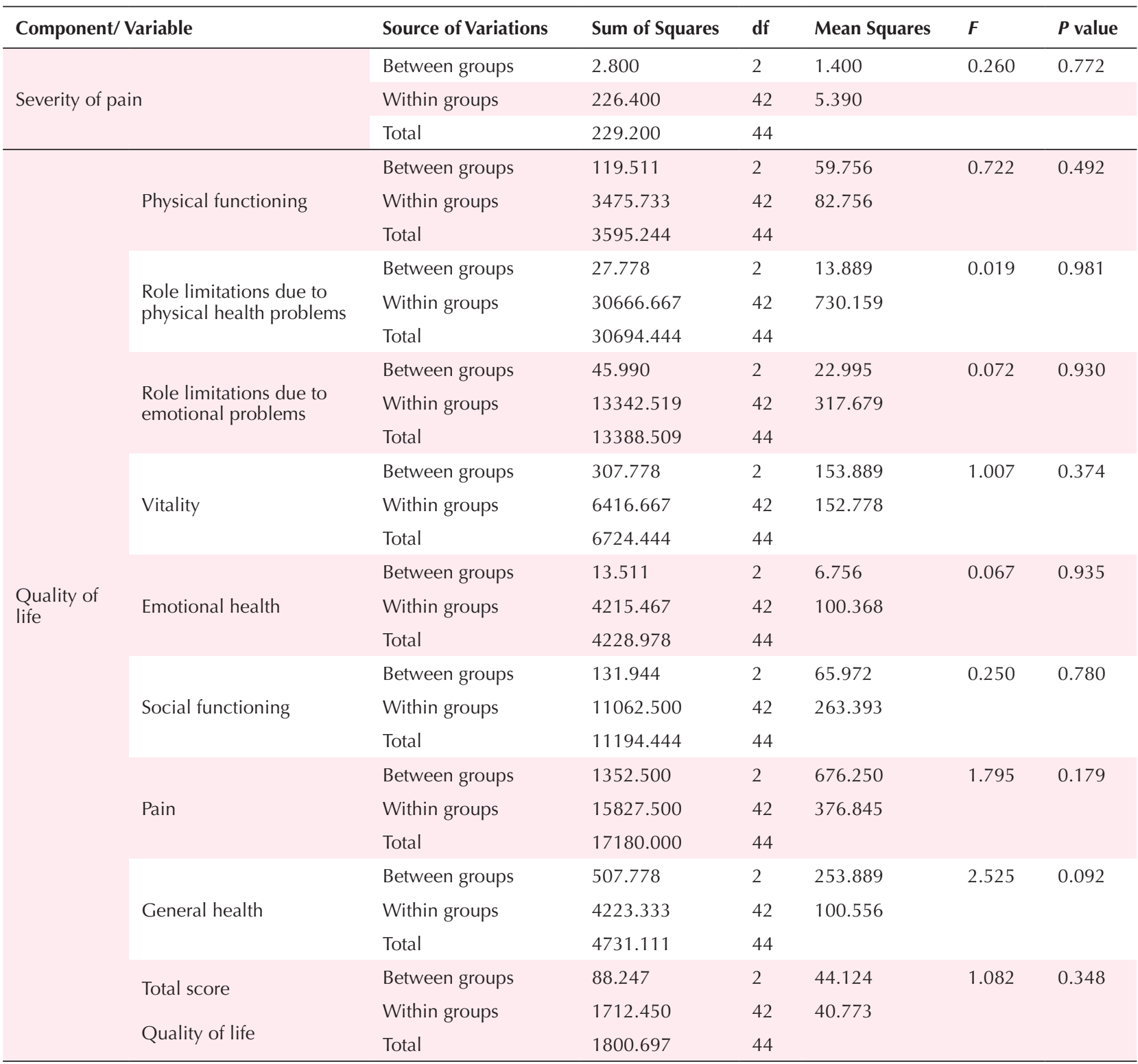

the quality of life. ${ }^{43}$ Kamani et $\mathrm{al}^{44}$ showed that acceptance and commitment-based therapy has significant effects on emotional, social, and physical functioning and leads to acceptance and reduction of pain in adolescents with chronic pain. According to their findings, this treatment also improves psychological flexibility and reduces depression symptoms in the parents.

Acceptance and commitment-based therapy work by active and productive confrontation with emotions, avoiding avoidance, changing attitudes toward oneself and challenges, reviewing values and goals of life, commitment to social goals, and psychological flexibility. ${ }^{45}$ Psychological flexibility is the main outcome of this treatment, which increases resilience and psychological well-being, and brings about a sense of calm and ultimately improves the quality of life. ${ }^{41}$ It could argue that acceptance is the main reason for the success of this treatment reducing the effect of painful experiences on emotional functions. Studies show that acceptance has 2 essential components. The first component is the experience of pain without trying to manage or avoid it. The second component is addressing life activities along with the experience of pain. ${ }^{44}$

Patients who are more willing to experience thoughts, undesirable memories, and emotional experiences tend to function better socially, physically, and emotionally. ${ }^{41}$ By performing defusion exercises (not to confuse oneself with the thoughts and feelings caused by illness), people can act more independently and consciously in the real world, and set themselves free from concentration on their narratives. This helps in using more effective coping styles, reducing stress and anxiety, improving the quality of life, ${ }^{45}$ and reducing pain. It could argue that one of the most apparent advantages of this treatment is that, unlike 
many other therapies, it does not impose any particular value or lifestyle on individuals, and clients decide about the required changes based on their values. Encouraging patients to identify their values and determine their goals, actions, obstacles, and ultimately by a commitment to them, people achieve their goals despite the problems. This leads to more satisfaction and improved quality of life. ${ }^{46}$

The results of this study regarding the effectiveness of mindfulness-based stress reduction and acceptance and commitment-based therapy in migraine patients indicate that they are equally effective. The similarities between the 2 therapeutic approaches can justify similar therapeutic outcomes. Psychological flexibility, values and abilities, emphasis on mindfulness and presence at the moment, acceptance, freedom from dissatisfactions, and committed action are common concepts in mindfulness and acceptance and commitment-based therapies. They reduce the severity of pain and improve the quality of life in people with migraines. Finally, it should note that like any other study, this research has also been subject to some limitations, including convenience sampling and not investigating some intervening variables. Therefore, caution should take in generalizing the results. In future studies, it has suggested that the effectiveness of both treatments should investigate for other rare conditions in the field of health psychology.

\section{Conflict of Interest Disclosures}

The authors declare that they have no conflict of interests.

\section{Ethical Statement}

All ethical principles considered in this article. The participants were informed about the purpose of the research and its implementation stages and signed the informed consent. They also assured about the confidentiality of their information. Moreover, they were allowed to leave the study whenever they wish, and if desired, the results of the research would be available to them.

\section{Acknowledgments}

We would like to thank all the employees and members of the neurology clinic of Imam Hossein hospital who helped in this project, and without their cooperation, this study would not have been possible.

\section{References}

1. Kaiser EA, Russo AF. CGRP and migraine: could PACAP play a role too? Neuropeptides. 2013;47(6):451-61. doi: 10.1016/j. npep.2013.10.010.

2. Aggarwal $M$, Puri $V$, Puri S. Serotonin and CGRP in migraine. Ann Neurosci. 2012;19(2):88-94. doi: 10.5214/ ans.0972.7531.12190210.

3. The International Classification of Headache Disorders, 3rd edition (beta version). Cephalalgia. 2013;33(9):629-808. doi: 10.1177/0333102413485658.

4. Martin BR, Seaman DR. Dietary and lifestyle changes in the treatment of a 23-year-old female patient with migraine. J Chiropr Med. 2015;14(3):205-11. doi: 10.1016/j. jcm.2015.09.001

5. Gordon-Smith K, Forty L, Chan C, Knott S, Jones I, Craddock $\mathrm{N}$, et al. Rapid cycling as a feature of bipolar disorder and comorbid migraine. J Affect Disord. 2015;175:320-4. doi: 10.1016/j.jad.2015.01.024.

6. Sadeghian H, Karimzadeh F, Jafarian M. Mechanisms involved in pathophysiology of different types of migraines. The Neuroscience Journal of Shefaye Khatam. 2013;1(9):504. [Persian].

7. Pietrobon D, Moskowitz MA. Pathophysiology of migraine. Annu Rev Physiol. 2013;75:365-91. doi: 10.1146/annurevphysiol-030212-183717.

8. Zarea K, Rahmani M, Hassani F, Hakim A. Epidemiology and associated factors of migraine headache among iranian medical students: A descriptive-analytical study. Clin Epidemiol Glob Health. 2018;6(3):109-14. doi: 10.1016/j. cegh.2017.10.002.

9. Kim SY, Park SP. The role of headache chronicity among predictors contributing to quality of life in patients with migraine: a hospital-based study. J Headache Pain. 2014;15:68. doi: 10.1186/1129-2377-15-68.

10. Kollewe K, Escher CM, Wulff DU, Fathi D, Paracka L, Mohammadi B, et al. Long-term treatment of chronic migraine with OnabotulinumtoxinA: efficacy, quality of life and tolerability in a real-life setting. J Neural Transm (Vienna). 2016;123(5):533-40. doi: 10.1007/s00702-016-1539-0.

11. Shaik MM, Hassan NB, Tan HL, Gan SH. Quality of life and migraine disability among female migraine patients in a tertiary hospital in Malaysia. Biomed Res Int. 2015;2015:523717. doi: 10.1155/2015/523717.

12. Shahrestani M, Qanbari BA, Nemati SH, Rahbardar H. The Effectiveness of Mindfulness Based Cognitive Group Therapy (MBCT) on Improving Perceived Infertility-Related Stress and Irrational Parenthood Cognitions among Infertile Women Undergoing IVF Treatment. The Iranian Journal of Obstetrics, Gynecology and Infertility. 2012;15(19):28-38. [Persian].

13. Anheyer D, Leach MJ, Klose P, Dobos G, Cramer $\mathrm{H}$. Mindfulness-based stress reduction for treating chronic headache: A systematic review and meta-analysis. Cephalalgia. 2019;39(4):544-55. doi: 10.1177/0333102418781795.

14. Frisvold MH, LindquistR, McAlpine CP. Living life in the balance at midlife: lessons learned from mindfulness. West J Nurs Res. 2012;34(2):265-78. doi: 10.1177/0193945911424171.

15. Zare H, Shahriari H, Zare M. Effect of Mindfulness-Based Stress Reduction on Students' Migraine Intensity. Journal of Zabol University of Medical Sciences and Health Services. 2014;6(3):30-9. [Persian].

16. Steurer J. [Mindfulness-based stress reduction is effective in patients with chronic lumbar backache]. Praxis (Bern 1994). 2016;105(12):721-2. doi: 10.1024/1661-8157/a002378.

17. Pettit J, Glickman-Simon R. Osteopathic Manipulative Therapy for Preterm Infants, Acupuncture for Menopausal Symptoms, Mindfulness-Based Stress Reduction for Chronic Low Back Pain, Chocolate for Ischemic Heart Disease, Berberine for Irritable Bowel Syndrome. Explore (NY). 2016;12(5):388-92. doi: 10.1016/j.explore.2016.06.015.

18. Crisp CD, Hastings-Tolsma $M$, Jonscher KR. Mindfulnessbased stress reduction for military women with chronic pelvic pain: a feasibility study. Mil Med. 2016;181(9):982-9. doi: 10.7205/milmed-d-15-00354.

19. Arefnasab Z, Babamahmoodi A, Babamahmoodi F, Noorbala AA, Alipour A, Panahi Y, et al. Mindfulness-based Stress Reduction (MBSR) and Its Effects on Psychoimmunological Factors of Chemically Pulmonary Injured Veterans. Iran J Allergy Asthma Immunol. 2016;15(6):476-86.

20. Nathan HJ, Poulin P, Wozny D, Taljaard M, Smyth C, Gilron 
I, et al. Randomized trial of the effect of mindfulness-based stress reduction on pain-related disability, pain intensity, health-related quality of life, and $\mathrm{A} 1 \mathrm{C}$ in patients with painful diabetic peripheral neuropathy. Clin Diabetes. 2017;35(5):294-304. doi: 10.2337/cd17-0077.

21. Bakhshani NM, Amirani A, Amirifard H, Shahrakipoor M. The effectiveness of mindfulness-based stress reduction on perceived pain intensity and quality of life in patients with chronic headache. Glob J Health Sci. 2015;8(4):142-51. doi: 10.5539/gjhs.v8n4p142.

22. Mehrdoost Z, Neshatdoost H, Abedi A. Effectiveness of acceptance and commitment therapy on the decrease of self-focused attention and improving self-efficacy. Journal of Psychological Models and Methods. 2013;3(11):67-81. [Persian].

23. Hayes SC, Levin ME, Plumb-Vilardaga J, Villatte JL, Pistorello J. Acceptance and commitment therapy and contextual behavioral science: examining the progress of a distinctive model of behavioral and cognitive therapy. Behav Ther. 2013;44(2):180-98. doi: 10.1016/j.beth.2009.08.002.

24. Prevedini AB, Presti G, Rabitti E, Miselli G, Moderato P. Acceptance and commitment therapy (ACT): the foundation of the therapeutic model and an overview of its contribution to the treatment of patients with chronic physical diseases. G Ital Med Lav Ergon. 2011;33(1 Suppl A):A53-63.

25. Müller R, Gertz KJ, Molton IR, Terrill AL, Bombardier CH, Ehde DM, et al. Effects of a tailored positive psychology intervention on well-being and pain in individuals with chronic pain and a physical disability: a feasibility trial. Clin J Pain. 2016;32(1):3244. doi: 10.1097/ajp.0000000000000225.

26. Dindo L, Recober A, Marchman J, O'Hara M, Turvey C. Depression and disability in migraine: the role of pain acceptance and values-based action. Int J Behav Med. 2015;22(1):109-17. doi: 10.1007/s12529-014-9390-x.

27. Bastami M, Goodarzi N, Dowran B, Dabaghi P, Bastami M. Effectiveness of acceptance and commitment therapy (ACT) to increase their quality of life of military personnel with type 2 diabetes mellitus. Journal of Nurse and Physician within War. 2016;12(4):119-26. [Persian].

28. Lee CE, Kim S, Kim S, Joo HM, Lee S. Effects of a mindfulnessbased stress reduction program on the physical and psychological status and quality of life in patients with metastatic breast cancer. Holist Nurs Pract. 2017;31(4):2609. doi: 10.1097/hnp.0000000000000220.

29. Omidi A, Momeni J, Raygan F, Akbari H, Talighi E. The effectiveness of mindfulness-based stress reduction program on quality of life among patients with cardiovascular diseases. Journal of Clinical Psychology Andishe va Raftar. 2017;11(42):7-16. [Persian].

30. Heshmati R, Ghorbani F. The effect of Mindfulness-Based Stress Reduction (MBSR) program on physical functioning and health related quality of life (HRQOL) in people with coronary artery disease (CAD). Cardiovascular Nursing Journal. 2016;5(3):16-25. [Persian].

31. Ardito RB, Pirro PS, Re TS, Bonapace I, Menardo V, Bruno E, et al. Mindfulness-based stress reduction program on chronic low-back pain: a study investigating the impact on endocrine, physical, and psychologic functioning. J Altern Complement Med. 2017;23(8):615-23. doi: 10.1089/acm.2016.0423.

32. Lindsay EK, Creswell JD. Mechanisms of mindfulness training: Monitor and Acceptance Theory (MAT). Clin Psychol Rev. 2017;51:48-59. doi: 10.1016/j.cpr.2016.10.011.

33. Janssen $M$, Heerkens $Y$, Kuijer $W$, van der Heijden B, Engels J. Effects of Mindfulness-Based Stress Reduction on employees' mental health: A systematic review. PLoS One. 2018;13(1):e0191332. doi: 10.1371/journal.pone.0191332.

34. Brown DB, Bravo AJ, Roos CR, Pearson MR. Five facets of mindfulness and psychological health: Evaluating a psychological model of the mechanisms of mindfulness. Mindfulness (N Y). 2015;6(5):1021-32. doi: 10.1007/s12671014-0349-4.

35. Mohammadi L, Salehzade Abarghoei $M$, Nasirian $M$. Effectiveness of acceptance and commitment therapy on cognitive emotion regulation in men under methadone treatment. Journal of Shahid Sadoughi University of Medical Sciences and Health Services. 2015;23(9):853-61. [Persian].

36. Reese ED, Zielinski MJ, Veilleux JC. Facets of mindfulness mediate behavioral inhibition systems and emotion dysregulation. Pers Individ Dif. 2015;72:41-6. doi: 10.1016/j. paid.2014.08.008.

37. Barbaro N, Pickett SM. Mindfully green: Examining the effect of connectedness to nature on the relationship between mindfulness and engagement in pro-environmental behavior. Pers Individ Dif. 2016;93:137-42. doi: 10.1016/j. paid.2015.05.026

38. Klein R, Dubois S, Gibbons C, Ozen LJ, Marshall S, Cullen $\mathrm{N}$, et al. The Toronto and Philadelphia Mindfulness Scales: Associations with satisfaction with life and healthrelated symptoms. International Journal of Psychology and Psychological Therapy. 2015;15(1):133-42.

39. Le TN. Mindfulness-based adventure camp for military youth. J Ext. 2014;52(2):1-10.

40. Zarnaghash M, Mehrabizadeh Honarmand M, Beshlideh K, Davoodi I, Marashi SA. The Effectiveness of MindfulnessBased Stress Reduction on Quality of Life and Resiliency of Veterans Spouses. Journal of Psychological Models and Methods. 2016;7(23):83-98. [Persian].

41. Darvish Baseri L, Dasht Bozorgi Z. Effectiveness of Group Therapy Based on Acceptance and Commitment on Cognitive Emotion Regulation and Alexithymia of Patients with Type 2 Diabetes. Iranian Journal of Psychiatric Nursing. 2017;5(1):714. doi: 10.21859/ijpn-05012. [Persian].

42. Kemani MK, Kanstrup M, Jordan A, Caes L, Gauntlett-Gilbert J. Evaluation of an intensive interdisciplinary pain treatment based on acceptance and commitment therapy for adolescents with chronic pain and their parents: A nonrandomized clinical trial. J Pediatr Psychol. 2018;43(9):981-94. doi: 10.1093/ jpepsy/jsy031.

43. Parsa M, Sabahi $P$, Mohammadifar M. The effectiveness of acceptance and commitment group therapy to improving the quality of life in patients with multiple sclerosis. J Clin Psychol. 2018;10(1):21-8. doi: 10.22075/jcp.2018.11686.1156. [Persian].

44. Gharaei-Ardakani S, Azadfallah P, Tavallaie A. The effectiveness of acceptance and commitment therapy on pain experience in women with chronic pain. J Clin Psychol. 2012;4(2):39-50. [Persian].

45. Rose MR, Norton S, Vari C, Edwards V, McCracken L, Graham $\mathrm{CD}$, et al. Acceptance and Commitment Therapy for Muscle Disease (ACTMus): protocol for a two-arm randomised controlled trial of a brief guided self-help ACT programme for improving quality of life in people with muscle diseases. BMJ Open. 2018;8(10):e022083. doi: 10.1136/ bmjopen-2018-022083.

46. Abbasi M, Mahmoudian $\mathrm{H}$, Rezvanifar S. Comparison of effectiveness between two educational methods of acceptance and commitment and emotional regulation training on psychological well-being in students with dyscalculia. J Res Educ 2014;1(1):23-35. [Persian]. 